\title{
Lisansüstü Eğitime Yönelik Farkındalığın Lisans Öğrencilerinin Lisansüstü Eğitim Niyetlerine Etkisi
}

\author{
İlhan İLTER ${ }^{1}$
}

\section{Öz}

$\mathrm{Bu}$ araştırmada henüz lisans programına devam eden üniversite öğrencilerinin lisansüstü eğitime yönelik farkındalık düzeylerinin lisans sonrası lisansüstü eğitim niyetlerini yordayıp yordama durumu incelenmiştir. Araştırma ilişkisel tarama modelinde yürütülmüştür. Araştırmanın örneklemini Türkiye'de bir devlet üniversitesinde eğitim fakültesinde öğrenim gören 350 öğrenci oluşturmaktadır. Verilerin toplanmasında Lisansüstü Eğitim Farkındalŭğ Ölçeği ve Lisansüstü Eğitim Niyeti Ölçeği kullanılmıştır. Araştırma verilerinin analizinde ise Pearson momentler çarpımı korelasyon katsayısı ve yapısal eşitlik modellemesi kullanılmıştır. Elde edilen bulgular, lisansüstü eğitime yönelik farkındalı̆̆ın lisansüstü eğitim niyetinin anlamlı bir yordayıcısı olduğunu göstermiştir. Araştırma sonuçları, lisansüstü eğitim hakkındaki farkındalık artışının henüz lisans eğitimi alan öğrencilerin lisans sonrası lisansüstü eğitime devam etme planları ve kararlarında pozitif ve anlamlı bir etkisinin olduğunu ortaya çıkararak ilgili alan yazına katkıda bulunmuştur. Buna göre yükseköğretimde lisansüstü eğitime yönelik farkındalığı geliştirmeye dayalı erken müdahaleler, bilgilendirici destek ve danışmanlık hizmetlerinin lisans öğrencilerinin gelecekte lisansüstü eğitime katılım oranlarını artıracağı öngörülmektedir. Bu araştırmanın sonuçları lisansüstü eğitimi planlama fikrini geliştirmede üniversitelere mevcut lisans öğrencilerine lisansüstü eğitime dair bilinçli bir farkındalık ve anlayış kazandırma noktasında önemli ipuçları vermektedir.

Anabtar Kelimeler: Lisansüstü Eğitim, Lisansüstü Eğitim Farkındalığı, Lisansüstü Eğitim Niyeti

The Effect of Postgraduate Study Awareness on Undergraduate Students' Postgraduate Study Intentions

\section{Abstract}

The current study, which used a relational screening model, investigated the effect of the awareness towards postgraduate study (PG) on the PG study intentions among undergraduate students. The sample of the study consisted of 350 currently undergraduate students enrolled in the faculty of education in a university in Turkey. Postgraduate Study Awareness Scale and Postgraduate Study Intention Scale were used to collect data for the study. The data were analyzed by using Pearson product-moment correlation coefficient and structural equation modeling. Results showed that the awareness towards PG study was a significant positive predictor of students' intentions to pursue PG studies. This study has contributed to the existing literature by exploring that the increased awareness about the PG study has a positive and significant effect on the plans and decisions of students who are currently enrolled in the bachelor's degree to continue pursuing postgraduate study. Early interventions, informative support, and guidance based on developing awareness may increase undergraduate students' participation rates in pursuing postgraduate studies. Findings provide important clues for universities to give current undergraduate students a conscious awareness and understanding of postgraduate study opportunities in developing the idea of pursuing postgraduate study.

Key Words: Postgraduate Study, Awareness about Postgraduate Study, Postgraduate Study Intention

\section{Atıf İçin / Please Cite As:}

İlter, İ. (2021). Lisansüstü Eğitime Yönelik Farkındalığın Lisans Öğrencilerinin Lisansüstü Eğitim Niyetlerine Etkisi. Manas Sosyal Araștormalar Dergisi, 10(3), 1592-1601.

Geliş Tarihi / Received Date: 22.10.2020

Kabul Tarihi / Accepted Date: 16.04.2021

\footnotetext{
${ }^{1}$ Doç. Dr. Kahramanmaraş Sütçü İmam Üniversitesi Eğitim Fakültesi, Sosyal Bilgiler Eğitimi ABD

iD ORCID ID: 0000-0002-4411-200X
} 


\section{Giriş}

Toplumların gereksinim duyduğu yüksek nitelikte (yetenekli, toplum ihtiyaçlarına ve gerçeklerine duyarl, üretken) insan gücünün yetiştirilmesinde lisansüstü niteliklerin (hem yüksek lisans hem de doktora seviyesi) önemli bir rolü vardır. Lisansüstü eğitim, bireyleri lisansüstü derecelere yönlendiren, bilimsel araştırma süreçleri ile bilgiye katkıda bulunabilecek ve gelişen sanayi ve toplum gereksinimlerini karşılayabilecek nitelikli bireyler yetiştirmeyi amaçlayan yüksek düzeyli bir öğretim faaliyetidir. Yükseköğretimin önemli bir parçası olan lisansüstü programlar, son yıllarda mezunların kariyer yollarını tanımlamaları için etkili ve güçlü bir yol haline gelmiştir. Bunun önem kazanmasının nedenleri arasında bilimsel araştırma ve yeni buluşlara duyulan gereksinim, küresel ölçekte rekabet gücü kazanma arzusu, yeni hizmet alanlarının oluşturulması, dünyada hızla gelişen ve değişen teknolojiler, sürdürülebilir kalkınmada nitelikli insan gücüne duyulan gereksinimin artması, yeni uzmanlık alanlarının ortaya çıkışı ve lisansüstü eğitim gören bireylerin genelde kamu kurumlarında, iş gücü piyasasında öncelikli olarak tercih edilmesi yer almaktadır (Groube, 2017, s. 2-6; Black ve Bonner, 2011, s. 163-164; Pelletier, Donoghue, Duffield, Adams ve Brown, 1998, s. 422).

Toplumda insanlardan sürekli olarak becerilerini geliştirmeleri gerektiğini savunan lisansüstü eğitim felsefesi, hayat boyu öğrenmeyi teşvik etmede önemli bir yere sahiptir (Anderson, Johnson ve Milligan, 1998, s. 10). Lisansüstü eğitim, üniversitelerin ve araştırmaların gelecekteki sağlığı için hayati bir önem taşır ve ekonomiyi büyütmek, yenilik ve kalkınmayı desteklemek için ihtiyaç duyulan ileri düzey becerileri sağlar. Lisansüstü eğitim toplumun çeşitli ihtiyaçlarını karşılar, bu nedenle bu eğitim daha fazla teşvik edilmeli ve lisansüstü eğitim olanakları da kolayca erişilebilmelidir. Smith (2010, s. 7) bilgi odaklı bir ekonomide lisansüstü düzeyde becerilere giderek daha fazla ihtiyaç duyulduğundan, lisansüstü programlardan yararlanma fırsatının herkese açı olması gerektiğini önermiştir. Bu tür bir eğitim bireylere meslek alanında ya da işgücü piyasasında etkili ilerlemeyi desteklemek için araştırma eğitimi ve beceri geliştirme olanakları sunabilmektedir.

Lisansüstü programlar, insanların çalışma ve kariyer alanlarını geliştirmelerine ya da değiştirmelerine olanak tanır. Lisansüstü öğretim, eğitimdeki perspektiflere ve kilit konulara derinlemesine araştırmalar sağlar. Ayrıca bu değişken işgücü piyasasında yaygın bir durumdur. Lisansüstü eğitim belirli bir süre boyunca bir alanda derinlemesine çalışma imkânı sunduğundan, birçok kişi tarafından en iyi öğrenme deneyimleri olarak kabul edilir. Bu deneyimler, bireyleri kim olduklarını, yaşamdan ne istediklerini düşünmeye teşvik etmekte ve onlara başarı için kapsayıcı yapılar ve süreçler sunmaktadır (Johnson ve Copnell, 2002; Purcell vd., 2012, s. 2-8; The British Academy, 2012, s. 6). Lisansüstü eğitim ayrica üniversitelere araştırmacı bir kimlik, akademik liderlik ve üretkenlik kazandıran; dolayısıyla bir üniversitenin en önemli çağcll işlevlerinden biri olarak tanımlanır. Bu eğitimin merkezini güncel tasarılar, eğitim teorileri, uygulamaları ve politikaları, kariyer planlamaları, ekip öğretimi ve teknoloji geliştirme çalışmaları oluşturmaktadır. Bu tarz bir eğitim, belirli bir alanda daha derin bir anlayış ve uzmanlık deneyimi sağlaması nedeniyle lisans derecesinden ayrılmaktadır (Aitken, Currey, Marshall ve Elliott, 2008, s. 70; Lee, Kim ve Jung, 2020, s. 638; O'Grady ve Cottle, 2015). Lisansüstü dersler, öğrencileri lisans seviyesinin ötesinde desteklemeyi ve onlara yükseköğretim sistemlerinin ve uygulamalarının rolü, amacı ve işlevi hakkında daha eleştirel bir anlayış geliştirmek için gerekli kaynakları sağlamayı amaçlamaktadır. Lisansüstü niteliklere sahip bireyler ise bilimin, teknolojinin ya da eğitimin ilerlemesinde daha aktif bir rol oynayabilmektedir. Bu roller ise inovasyon bilgisi, geliştirilmesi ve uygulanması ve bilgi aktarımı faaliyetleri ve dolayısıyla iş geliştirme ve yatırımın anahtarıdır (Austin ve Vallely, 2014, s. 22; The British Academy, 2012, s. 6; Wang, 2018, s. 239).

Bilindiği üzere lisans eğitimi, öğrencilerin kariyerleri hakkında kararlar aldıkları kritik bir dönemdir. Mezuniyet sonrası istihdam firsatları ve verimli çalışma koşullarını sağlaması düşüncesi, bireylerin lisansüstü hedeflerini etkilemektedir. Lisansüstü eğitim, zorunlu olmamakla birlikte tüm bilim dallarında lisans düzeyinde eğitimini tamamlayan her birey için, kişisel becerilerin geliştirilmesi, mesleki tanınma ve statü için bir firsat olduğundan lisansüstü yeterliliklere sahip olmak bir zorunluluk haline gelmiştir (Ohnishi ve Ford, 2015, s.58; Wisker, 2007, s.9). Nitekim McCullocha ve Liz Thomas (2013, s.215) öğrencilerle ilgili olarak, işgücünün giderek artan oranının lisans niteliklerine sahip olduğu bir durumda mezunların kendilerine rekabet avantajı sağlamak için lisansüstü niteliklere sahip olmayı arzulamalarının oldukça makul olduğunu savunmuştur. Ayrica bir alanda yeni bilgi ve becerileri kazanmaya gereksinim duyan bireyler lisansüstü programlara başvurmayı kariyer planlamada bir çözüm yolu olarak görmektedir. Çünkü 
lisansüstü dereceler bireylerin kariyer gelişimlerini gerçekleştirebilecekleri en iyi yollardan biri olarak tanımlanmaktadır.

Araştırmalar lisansüstü eğitimin istihdam beklentilerini artırmak, mevcut kariyer yolunda ilerlemek, daha yüksek akademik veya araştırma yeterliliği seviyesine ulaşmak için yapıldığını göstermiştir (Anderson vd., 1998, s.10; Kulej ve Wells, 2009; Park ve Wells, 2010, s.16). Lisansüstü eğitimin gelecekteki kariyer ve maaş üzerinde olumlu bir etkisinin olduğunu gösteren araştırmalar da mevcuttur (Barber, Pollard, Millmore ve Gerova, 2004, s.x). Alan yazında var olan araştırmalar kariyer gelissimine yatırım yapmada lisansüstü eğitimin motive edici ve istikrarlı bir yol olduğunu göstermiştir (Stuart, Lido, Morgan, Solomon ve Akroyd, 2008, s.3). Jepsen ve Neumann (2010, s.457) bir alanda lisansüstü eğitim yapmanın çoğunlukla profesyonel niteliklere sahip olmaya öncülük ettiğini savunmuştur. Bu tür bir eğitim, bireylerin hangi alanda uzmanlaşmak istedikleri, bu konuda nasıl ilerleyeceklerini ve kariyer hedeflerine ulaşmak için nasıl başarılı bir şekilde çalışacaklarını net bir şekilde görmelerini yardımcı olmaktadır (Wisker, 2007, s.45). Araştırmacılara göre lisansüstü eğitimin amac1, pratik yeni bilgi veya anlayış kazanmak, nitelik ve kişisel öğrenmeyi geçekleştirmek, istihdam olasılıklarını artırmak, mevcut yeterlilikleri, kaynakları geliştirmektir (Austin ve Vallely, 2014, s.23; İlter, 2020a; Richards ve Potgleter, 2010, s.143). Bu etkinlikler, lisansüstü eğitim alma konusunda farkındalı̆̆ ve coşkuyu artırabilmektedir.

Lisansüstü eğitim farkındalı̆̆ı lisansüstü çalışmalara katılımı amaçlamak ve bu çalşmaları deneyimlemek ile ilgilidir. Lisansüstü eğitim konusundaki farkındalık, lisansüstü eğitim bilgisi, lisansüstü eğitim seçenekleri, lisansüstü eğitime giriş koşulları, lisansüstü dereceler ve lisansüstü eğitimin katkıları hakkında bilgi ve farkındalığa sahip olmayı tanımlar (İlter, 2020b, s.120; Jepsen ve Varhegyi, 2011, s.609). Lisansüstü çalışmalara dair farkındalık, lisansüstü düzeyde eğitim hedefi için kilit bir yeterliliktir. Bu faktörün önemli olmasının birkaç nedeni bulunmaktadır. Birincisi, lisansüstü eğitime yönelik farkındalık öğrencilerin kariyer amaçlarını etkilemede birincil adımdır. Kendisini belirli bir kariyer yoluna yönlendiren bir birey mezuniyet sonrası eğitim ve kariyer firsatları için bilgi ve anlayış edinmeye çalışabilir. Kariyer kararı öncesi birey konu, seçim veya kariyer planlaması hakkında bilgileri toplama eğilimindedir. Psikoloji, eğitim ve iletişimde kullanılan ve Bandura'nın (1986) genel Sosyal Bilişsel Kuramına dayanan Sosyo-Bilişsel Kariyer Kuramında ise kariyer seçimi ve gelişimi için öz-farkındalı̆ı̆n gerekli bir öncül olduğu öne sürülmektedir (Lent, Brown ve Hackett, 1994, s.37). Kişinin kendi ilgi alanlarının, seçimlerinin ve yeterliliklerinin farkında olması seçilen bir kariyer hakkında bilgiye erişim, gerçekçi ve seviyeye uygun hedeflerin seçimi, seçilen hedefle ilgili planlar yapma ve zorluklarla başa çıkma arayışları ve bunların belirlenmesinde önemli bir rol oynamaktadır (Bolat ve Odacı, 2017, s. 253). Buna göre bir öğrencinin lisansüstü eğitimin seçenekleri, avantajları ve öncelikleri hakkındaki farkındalığı lisansüstü hedeflerine dayalı karar verme süreçlerinin bir habercisi olabilir. Araştırmacılar öz-farkındalığın kariyer kararlarında içsel ve dışsal etkilerin izleme ve denetlemesini gerektirdiğini savunmuştur (Ö̈zyürek, 2013, s.103). Ögrenciler öz-farkındalıkları yoluyla kariyer karar verme sürecini izleyerek ve kontrol ederek, karar verme yollarını denetleyebilirler. Bu nedenle farkındalık kariyer gelişimi sürecinin ya da kariyer seçim sürecinin değerli bir parçası olarak kavramsallaştırllır (Wakeling, 2009, s.90). Bu bilgiler farkındalığın bireylere kariyer kararı vermelerinde bir bakış açısı sağladığını göstermektedir. İkincisi, henüz lisans eğitiminin başlangıcında gelecekte kariyer gelişimini desteklemek isteyen öğrenciler, kariyer hakkında bilgi edinme arayışındadır. Bu da muhtemelen istihdam firsatları ve kariyer seçenekleri için geniş bir bilgi arayışına yol açar (Jepsen ve Neumann, 2010, s.457). Üçüncüsü, kariyer planlama faaliyetleri, üniversitelerinin öğrencilerin mezuniyet sonrası eğitim olanaklarına katılımı için yürüttükleri faaliyetleri de önemlidir. Kariyer gelişimine odaklanan üniversiteler, lisansüstü programlar ile ilgili akademik diyaloglar ve tanıtım çalışmaları aracillğıyla öğrencilerin kariyer karar verme öz-yeterlilik düzeylerini artırarak lisansüstü eğitime devam etme konusundaki niyetlerini artırma çabasındadır (Neumann, 2003, s.85). Hâlihazırda lisans eğitimi alan öğrenciler, lisansüstü çalışmaların kapsamına ilişkin farkındalık düzeylerini artırdıklarında, bu farkındalık, kariyer seçenekleri hakkında detaylı bilgi edinmelerini ve kariyer karar verme sürecinde gerekli becerileri kullanmalarını sağlamaktadır. Bu nedenle, lisansüstü olanaklara dair farkındalığın öğrencilerin lisansüstü çalışmalara katılım kararlarını şekillendireceği öngörülmektedir.

\section{Araştırmanın Amacı}

$\mathrm{Bu}$ çalışmada üniversite öğrencilerinin lisansüstü eğitime yönelik farkındalık düzeylerinin lisans sonrası lisansüstü eğitim ile ilgili niyetleri üzerinde etkisinin olup olmadığ1 yapısal eşitlik modellemesi kullanılarak test edilmiştir. Mevcut lisans öğrencilerinin lisansüstü eğitime yönelik farkındalıklarının lisansüstü eğitime devam etme konusundaki niyetleri üzerinde etkili olup olmadığının belirlenmesi bu araştırmanın çıkış noktasını oluşturmaktadır. Üniversite öğrencilerinin lisansüstü eğitime katılma 
hedeflerini etkileyen faktörlerin araştırılması önemlidir. Bu faktörlerin incelenmesi, öğrencilerin bilinçli mesleki veya kariyer seçimleri yapabilmeleri için öz-yeterliliklerine dair bir farkındalığa sahip olmalarını sağlayabilir. Lisansüstü eğitime yönelik farkındalık ve lisansüstü eğitim alma konusundaki niyet arasındaki ilişkinin belirlenmesi üniversite öğrencilerinin lisans sonrası kariyer amaçları ve bu amaçların şekillendirilmesine dahil olan süreçlerin daha iyi anlaşılmasına kaynaklık edebilir. Sonuç olarak lisansüstü eğitim alma niyetlerini etkileyen olası faktörlerin belirlenmesi dayalı bir çalışmanın yapılması yerinde olacaktır. Bu amaç kapsamında aşağıda verilen hipotez test edilmiştir.

Hipotez: Lisans öğrencilerinin lisansüstü eğitim hakkındaki farkındalık düzeyleri lisans sonrası lisansüstü eğitim alma konusundaki niyetlerini pozitif yönde yordamaktadır.

\section{Yöntem}

\section{Araştırmanın Deseni}

Üniversite öğrencileri örnekleminde lisansüstü eğitime yönelik farkındalık ile lisansüstü eğitim niyeti değişkenleri arasındaki ilişkilerin incelendiği bu araştırma, ilişkisel tarama modelinde yürütülmüştür. Araştırmada lisansüstü eğitime yönelik farkındalığın üniversite öğrencilerinin lisans sonrası lisansüstü eğitim alma konusundaki niyetlerini yordama durumu incelenmiştir. Değişkenler arasındaki ilişkileri belirlemek için bir hipotez modeli oluşturulmuştur. Değişkenler arasındaki ilişkileri belirlemek için yapısal eşitlik modellemesi (YEM) kullanılmışır (Kline, 2015).

\section{Evren ve Örneklem}

Araştırmanın örneklemini 2019-2020 öğretim y1lı güz yar1-yllı döneminde bir yükseköğretim kurumunun eğitim fakültesi farklı programlarda son sinıfta öğrenim gören öğrenciler oluşturmaktadır. Evrenden hedeflenen örneklem grubuna ulaşmak için basit tesadüfi örnekleme yöntemi kullanılmıştır. Buna göre araştırmanın çalışma grubunu 195 kadın ve 155 erkek olmak üzere 350 üniversite öğrencisi oluşturmaktadır.

\section{Veri Toplama Araçları}

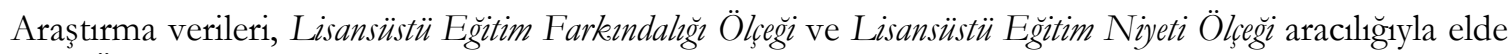
edilmiştir. Ölçme araçlarına ilişkin bilgiler aşağıda sunulmuştur.

Lisansïstü Eğitim Farkındalğ̆ Ölçeği: Bu araştırmada katıllımcıların lisansüstü eğitime yönelik farkındalık düzeylerini belirlemek için yazar (İlter, 2020b) tarafindan geliştirilen "Lisansüstü Eğitim Farkındalı̆ğ Ölçeği” kullanılmıştır. Ölçek tek bir boyuttan ve toplam altı maddeden oluşmaktadır. Ölçek beşli likert tipinde derecelendirilmiştir ( $1=$ Hiç katılmıyorum, 5= Tamamen katıllyorum). Ölçekte yükselen puanlar lisansüstü eğitimin önemi, kariyer gelişimi açısından önemi, lisansüstü eğitimin katkıları, lisansüstü dereceler hakkında bilgi düzeyi ve lisansüstü programlara başvuru koşulları konusundaki farkındalı̆ı̆n yüksekliğine işaret etmektedir. Ölçekte örnek maddeler (1) "Lisansüstü eğitimi, kariyer seçimi ve kariyer planlama ile ilgili kararlarda önemli bir yardım alma yolu olarak görüyorum”. (2) "Lisansüstü programlar ve verilen dereceler hakkında nereden, kimden veya nasıl bilgi alınacağını biliyorum." ve (3) "Lisansüstü eğitimin bir alanda uzmanlaşmanın önemli bir gereği olduğunu düşünüyorum." Ölçeğin yapı geçerliğini belirlemek için yazar tarafindan üniversite örneklemi üzerinde gerçekleştirilen doğrulayıcı faktör analizi (DFA) sonuçlarında ölçeğin tek faktörlü yapısının iyi uyum gösterdiği bulunmuştur: RMSEA= .06, GFI= . 93, CFI $=.95$, IFI = .95. Ölçeğin Cronbach Alfa (iç tutarlık) katsayısı ise .88 olarak belirlenmiştir (İlter, 2020b, s.128). Bu araştırmada ise Lisansüstü Eğitim Farkındalığı Ölçeğinin Cronbach Alfa katsayısı .78 olarak hesaplanmıştır.

Lisansüstü Eğitim Niyeti Ölçĕğ: Katılımcılarnn lisansüstü eğitim ile ilgili niyetlerini belirlemek için yazar (İlter, 2020b) tarafindan geliştirilen "Lisansüstü Eğitim Niyeti Ölçeği’" (LENÖ) kullanılmıştır. Ölç̧ek toplam altı maddeden ve tek faktörlü bir yapıdan oluşmaktadır. Ölçekteki maddeler beşli Likert tipi derecelendirmeye dayalı olarak yapılandırılmıştır. Ölçekteki maddeler henüz lisans programına devam eden öğrencilerin lisans sonrası lisansüstü eğitim alma kararını ve bu kararın gerekçelerini, lisansüstü eğitimin gerekliliği konusundaki düşüncelerini, lisansüstü programlara giriş için gerekli koşulları sağlayıp sağlamama hazırlıklarını belirlemeyi amaçlamaktadır. Ölçekte örnek maddeler (1) "Lisansüstü eğitim, akademik odaklı kişisel yeteneklerimi ve performansını geliştirme fırsatıdır." (2) Lisans eğitimini tamamladıktan sonra, lisansüstü düzeyde öğrenim görmek için gerekli koşulları sağlamaya çalısıyorum”. Ölçekte yükselen puanlar lisans sonrası bir lisansüstü programa devam etme konusundaki niyetlerin yüksekliğine işaret etmektedir. 
Ölçeğin yap1 geçerliliği için yazar tarafindan üniversite örnekleminde açımlayıcı (AFA) ve doğrulayıc1 faktör analizleri (DFA) gerçekleştirilmiştir. AFA sonuçları ölçeğin toplam varyansının \% $\% 5$ 'ini açıklayan tek faktörlü bir yapı sergilediğini göstermiştir. DFA sonuçlanı ise ölçeğin tek faktörlü yapısının iyi uyum gösterdiğini ortaya koymuştur: RMSEA $=.061$; GFI $=.92$; CFI $=.95$; IFI $=.95$. Ölçeğin güvenirlik çalışmaları sonucunda Cronbach alfa katsayısının .85 olduğu görülmüştür (İlter, 2020b, s.130). Bu araştırma kapsamında ise LENÖ'nün Cronbach Alfa katsayısı incelenmiş ve .80 olarak hesaplanmıştır.

\section{Verilerin Toplanmas1}

Araştırma öncesi gerekli etik ve veri toplama izinleri alınmıştır. Bu adımdan sonra araştırmacı (yazar) tarafindan Lisansüstü Eğitim Farkındalığı Ölçeği ve Lisansüstü Eğitim Niyeti Ölçeğinden oluşan bir veri toplama kitapçı̆̆ hazırlanmıştır. Veri toplama araçları tüm katılımcılar için öğrenim gördükleri sınıf ortamında yazar tarafindan uygulanmıştır. Yazar katılımcılara bu çalışmanın amacı, veri toplama araçlarını doldurma kriterleri hakkında sözlü olarak bilgi vermiştir. Bu yolla araştırma için toplam 350 öğrenciden veri elde edilmiştir. Toplanan veriler SPSS 22.00 ve AMOS 22.0 programları kullanılarak analiz edilmiştir. Verilerin ön incelemesi yapılarak, eksik bırakılan ve güvenilir olarak doldurulmayan herhangi bir veri toplama aracının olmadığı görülmüştür. Bu adımdan sonra çok değişkenli normallik varsayımının karşılanması için tek değişkenli normallik için her bir değişkene yönelik çarpıklık ve basıklı değerleri hesaplanmıştır (Kline, 2015). Buna göre lisansüstü eğitim farkındalığı değişkenine ait çarpıklık katsayısı 1.065, basıklık katsayısı ise .789 olarak hesaplanmıstır. Lisansüstü eğitim niyeti değiş̧keni için çarpıklık katsayıs1 -.879 ve basıklık katsayıs1 .872 olarak bulunmuştur. Bütün bu değerlerin -1.5 ile +1.5 değerleri arasında yer alması araştırmada yer alan bütün değisskenlerin normal bir dağılıma sahip olduklarını göstermektedir (Tabachnick ve Fidell, 2013). Araştırmada lisansüstü eğitim farkındalığı (bağımsız değişken) ile lisansüstü eğitim niyeti (bağımlı değişken) arasındaki ilişkiyi belirlemek amacıyla için Pearson momentler çarpımı korelasyon katsayısı hesaplanmıştır. Bağımsız değişkenin bağımlı değişkeni yordayıp yordamadığını belirlemek için ise yapısal eşitlik modellemesi kullanılmıştır. Çalışmada uyum iyiliği indeksleri olarak ki-kare $(\chi 2)$ ve serbestlik derecesinin (sd) oranı ile birlikte GFI, CFI, TLI ve RMSEA değerleri tercihe dilmiştir. Kabul noktasını betimleyecek olan kritik değerler olarak; $\chi^{2} /$ sd $\leq 5$; GFI, IFI, CFI ve TLI $\geq$.90; RMSEA $\leq .80$ kabul edilmiştir (Hu ve Bentler, 1999; MacCallum, Browne ve Sugawara, 1996). Modelde Ki-kare değerinin yorumlanmasında; $\chi 2 /$ sd değerinin 5 'ten küçük olması modelin yeterliliğini, RMSEA değerinin .05 ile .08 aralığında yer alması modelin iyi uyuma sahip olduğunu göstermektedir (Schumacker ve Lomax, 1996). GFI, CFI ve TLI değerlerinin .90 ve üstünde değer alması ise iyi uyumu göstermektedir. Verilerin yorumlanmasında $\mathrm{p}<.05$ anlamllık düzeyi temel alınmıştır.

\section{Bulgular}

\section{Değişkenler Arasındaki Korelasyonlar}

Araştırma kapsamında ele alınan değişkenlere ait betimsel istatistikler ve korelasyonlar incelenmiştir. $\mathrm{Bu}$ amaçla lisansüstü eğitim farkındalığı ve lisansüstü eğitim niyeti değişkenleri arasındaki korelasyonlar incelenmişsir. Elde edilen sonuçlar Tablo 1'de verilmiştir.

Tablo 1. Araştırma Değğskenleri İ̧in Korelasyon, Ortalama ve Standart Sapma Değerleri

\begin{tabular}{|c|c|c|c|c|c|}
\hline & \multirow{2}{*}{ Değişken } & \multirow{2}{*}{ Ortalama } & \multirow{2}{*}{ Standart Sapma } & \multicolumn{2}{|c|}{$r$} \\
\hline & & & & 1 & 2 \\
\hline 1. & Farkındalık & 3.43 & 7.58 & - & $.396^{*}$ \\
\hline 2. & Niyet & 3.77 & 11.42 & & - \\
\hline
\end{tabular}

Tablo 1'deki analiz sonuçları incelendiğinde korelasyon analizi sonuçları, lisansüstü eğitime yönelik farkındalığın lisansüstü eğitim niyeti ile pozitif yönde ilişkili olduğunu göstermiştir $(r=.396 ; \mathrm{p}<.001)$. Buna göre lisans öğrencilerinin lisansüstü eğitim hakkındaki farkındalık düzeyleri artıkça lisans sonrası lisansüstü eğitime başlama konusundaki niyetlerinin de artı̆̆ ifade edilebilir.

\section{Yapısal Eşitlik Modellemesine İlişkin Bulgular}

Araştırmanın amac1 doğrultusunda üniversite öğrencilerinin lisansüstü eğitime yönelik farkındalıklarının lisansüstü eğitimle ilgili niyetlerini yordama düzeyine ilişkin kurulan modelin testine dair sonuçları Şekil 1'de verilmiştir. 


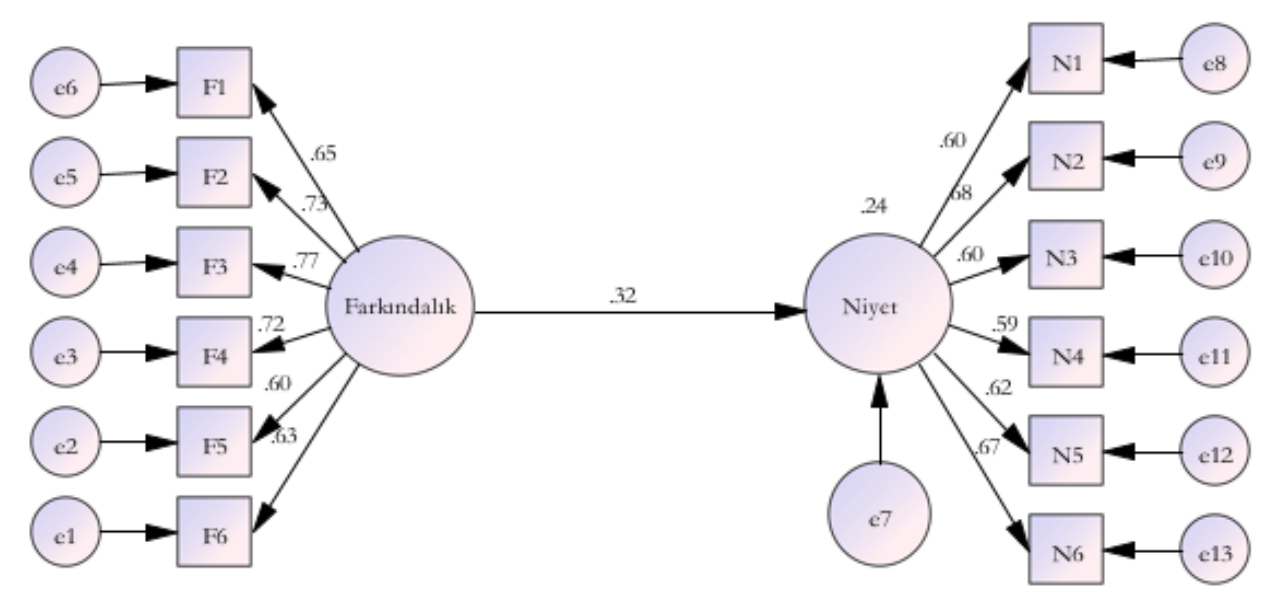

Şekil 1. Araştırmada Doğrulanan Hipotez. Model

Lisansüstü eğitime yönelik farkındalığın lisansüstü eğitim niyeti üzerindeki etkisini belirlemeye dayalı kurulan modelin testi sonucunda; lisansüstü eğitim niyetinin lisansüstü eğitime yönelik farkındalık tarafindan pozitif yönde yordandığı bulunmuştur $(\beta=.32, \mathrm{p}<.001)$. Kurulan modelde elde edilen uyum indekslerinin ise yeterli düzeyde olduğu ve modelin istatistiksel olarak doğrulandığı görülmüştür $\left(x^{2} / \mathrm{sd}=\right.$ $2.75, \mathrm{p}<.001, \mathrm{RMSEA}=.061, \mathrm{IFI}=.94, \mathrm{CFI}=.94$, GFI $=.93$, TLI $=.94)$. Lisansüstü eğitime yönelik farkındalığın öğrencilerin lisansüstü eğitim niyeti üzerindeki açıladığ1 varyansın $\% 24$ olduğu görülmüştür. $\mathrm{Bu}$ sonuçlara göre üniversite öğrencilerinin lisansüstü eğitim olanakları ve seçenekleri hakkındaki farkındalıkları öğrencilerin gelecekteki lisansüstü hedeflerine dair düşünce yapılarını pozitif yönde şekillendirmektedir.

\section{Tartışma, Sonuç ve Öneriler}

Bu çalışmada lisans programına devam eden son sınıf öğrencilerinin lisansüstü eğitim hakkındaki farkındalıklarının lisansüstü eğitim alma konusundaki niyetlerini yordayıp yordamadığı incelenmiştir. Korelasyon analizi sonuçlarında lisansüstü eğitime yönelik farkındalık ile lisansüstü eğitim niyeti arasında anlamlı bir ilişki bulunmuştur. Yapısal eşitlik modellemesine ilişkin elde edilen bulgular ise lisansüstü eğitime yönelik farkındalığın üniversite öğrencilerinin lisansüstü eğitim niyetlerini pozitif yönde yordadığını göstermiştir. Araştırma sonuçları lisans öğrencilerinin lisansüstü eğitim hakkındaki farkındalık düzeylerinin lisansüstü eğitim niyetlerini anlamlı ölçüde artırabileceğini ortaya koymuştur. Başka bir ifadeyle öğrencilerin lisansüstü eğitimin seçenekleri, avantajları ve öncelikleri, eğitim süreci bilgisi hakkındaki farkındalıklarının lisans sonrası lisansüstü eğitim almayla ilgili eğilimlerini olumlu yönde şekillendirdiği görülmüştür. Elde edilen bu sonuç, beklendiği üzere lisans sonrası eğitim olanaklarına dair farkındalı̆̆ın öğrencilerin gelecekte bu eğitime başlama konusundaki niyetlerini artırmada anlamlı bir etkiye sahip olabileceğini göstermektedir. Buna göre lisansüstü eğitim hakkındaki farkındalığın üniversite öğrencilerinin lisansüstü eğitime dair düşüncelerini etkilemede içsel motivasyon özelliğine sahip olduğu ifade edilebilir.

Araştırma bulguları öğrencilerin lisansüstü eğitim hakkındaki farkındalık düzeylerine bakılarak lisans sonrası bir lisansüstü programa başlamayla ilgili niyetlerinin yordanabileceğini göstermektedir. Bu anlamda lisansüstü eğitim farkındalığının öğrencilerinin lisansüstü eğitimi planlama ve lisansüstü programlarla etkili bağlantı kurmalarına yardımcı olmak isteyen üniversiteler tarafindan dikkate alınması gereken kilit bir faktör olduğu ifade edilebilir. Öğrencilerin farkındalık düzeylerinin yükseltilmesi, gelecekte onlara lisansüstü eğitime katılımda kararlı bir bağlllığı artıracağı olası görünmektedir. Elde edilen bulgular Super'in (1980) kariyer olgunluğu kavramı temel alınarak açklanabilir. Bu kavram performansı izleme, bilgiyi kullanma, kariyer fırsatlarını araştırma, kariyer seçimi ile ilgilenme ve kariyer planları yapabilme ile ilgilidir. Araştırmacılar kariyer geliştirme sürecinde farkındalık ve bilginin kariyer kararı verme öz-yeterliliğini tanımlayan kariyer olgunluk düzeyini artıracağını savunmuştur (Patton ve Creed, 2001; Powell ve Luzzo, 1998, s. 145). Kariyer olgunluğuna sahip bireyler kariyer seçimleri yapabilmek için gerekli koşulların farkında olup, seçimlerini gerçekçi ve tutarlı biçimde oluşturabilir (Lent, Brown ve Hackett, 2000, s. 5; Ünsal, 2014, s. 314). Kariyer olgunluğu ise kariyer karar verme konusundaki bilgi ve farkındalık temelinde kariyer kararları almaya hazırlığın bir ölçüsüdür. Bireyin bilinçli kariyer kararları almaya ve kariyer geliştirme görevleriyle başa çıkmaya hazır olup olmadığını ifade eder (Powell ve Luzzo, 1998, s. 146; Savickas, 1984). Öğrencilerin kariyer olgunluk düzeyleri ne kadar güçlüyse, mümkün olduğunu 
düşündükleri kariyer seçenekleri ne kadar fazla olursa, onlara o kadar çok ilgi gösterirler, kendilerini farklı arayışlara daha iyi hazırlarlar ve akademik derslerindeki 1srarı ve başarıları o kadar artmaktadır (Betz ve Hackett, 1986; Lent vd., 1994). Savickas' a (1990) göre yüksek kariyer olgunluğuna sahip kişiler kariyer karar verme süreci hakkında daha fazla farkındalık sergilerler, mevcut davranışlarını gelecekteki hedeflerle ilişkilendirirler, kariyer kararları verirken yüksek düzeyde özgüvene sahiptirler ve kariyer seçimleri yapmaya kararlıdırlar. Bu araştırmanın sonuçları çalışmaya katılan lisans öğrencilerinin lisansüstü eğitime devam etme kararlarının gelecekteki hedeflerle ile ilgili olarak lisansüstü eğitim seçeneklerini araştırma ve anlama ihtiyaçlarından etkilendiğini göstermektedir.

Mevut araştırma üniversite öğrencilerini lisansüstü dereceleri almaya teşvik etmek için önemli çıkarımlar sağlamaktadır. Birincisi lisansüstü eğitimi planlama etkinlikleri kapsamında üniversitelerin mevcut lisans öğrencileri için lisansüstü programlara ilgi ve farkındalığı artırmayı hedeflemesi halinde, bunun öğrencilerin lisansüstü kararlanını olumlu yönde etkilemesidir. Nitekim Austin ve Vallely (2014, s. 29) kariyer karar verme sürecinde farkındalık artışının öğrencilerin lisansüstü eğitim almaya teşvik etmek için etkili bir kaynak olduğunu savunmuştur. Bu anlamda üniversiteler lisansüstü eğitim hakkında farkındalığı ve firsatlara dair farkındalığı artırmak için lisansüstü programlarla ilgili tanıtım faaliyetleri, bilgi kaynakları, çalıştaylar düzenleyerek ya da fakülte-öğrenci etkileşimine dayalı mentorluk faaliyetleri/merkezleri oluşturarak öğrencilerin kariyer kararını etkileyebilir. Bunun da lisansüstü eğitime katılım ile uyumlu olabileceği düşünülmektedir. Hearn (1987, s. 135) fakülte-öğrenci etkileşiminin ve bölüm bağlamının, lisans öğrencilerinin lisansüstü eğitim alma niyetlerinin güçlü yordayıcıları olduğunu belirlemiştir. İkincisi, ögrencilere lisansüstü derecelere, özellikle de doktora derecelerine dair farkındalık kazandırıldığında bunun öğrencilerin ana motivasyonlarını ve başarılarını olumlu yönde şekillendireceği düşünülmektedir. Bu sayede, öğrenciler çalışmalarını sürdürmek ya da daha yüksek dereceler almaya devam etmek için daha rasyonel ve bilinçli olarak karar verebilirler. Dolayısıyla lisansüstü çalışmalara katılımı genişletme konusunda anlamlı bir farkındalık yaratmak için lisansüstü eğitime başlama fikri erkenden ögrencilerin aklına yerleştirilmesi önerilmektedir. Böylece, lisans öğrenimine başlayan öğrenciler bu fikri anlayacak ve lisansüstü programlarla etkili bağlantı kurmak için gerekli olan bilgi ve becerileri kazanmak adına yeterli zamana sahip olabilecektir. Üçüncüsü, mezunların lisans derecesinden sonra ne yapacağından emin olmadığ durumlarda önleyici bir strateji olarak belirli bir iş ya da mesleğe giriş için lisansüstü niteliklerin gerekli olduğuna dair bir farkındalığın öğrencilere erkenden kazandırılması yerinde olacaktır. Erken müdahale ve iyileştirilmiş bilgi ve rehberliğin öğrencilerin kariyerlerini etkili bir biçimde yönetmelerine yardımcı olarak lisansüstü eğitime katılım oranlarını artırabilir. Sonuç olarak bu araştırmada kurgulanan modelde doğrulandığı gibi lisansüstü eğitimde farkındalığı ve ilerlemeyi artırmayı amaçlayan kariyer etkinliklerin mezunlarla sınırlı kalmaması, üniversiteye yeni kayıtlı öğrencileri de içermesi önerilmektedir. Ayrıca üniversiteler, öğrencilere akademik başarı, kariyer farkındalığı gibi ilerleme hakkında daha anlamlı ve düzenli geri bildirim sağlayarak lisansüstü eğitime geçişi teşvik etmek için öğrencilerinin ilerlemesini daha yakından izlemeli ve değerlendirmelidir (Neumann, 2003, s.xv).

\section{Etik Beyan}

"Lisansüstü Eğitime Yönelik Farkındalğın Lisans Öğrencilerinin Lisansüstü Eğitim Niyetlerine Etkisi” başlıklı çalışmanın yazım sürecinde bilimsel kurallara, etik ve alıntı kurallarına uyulmuş; toplanan veriler üzerinde herhangi bir tahrifat yapilmamış ve bu çalışma herhangi başka bir akademik yayın ortamına değerlendirme için gönderilmemiştir. Gerekli olan etik kurul izinleri Kahramanmaraş Sütçü İmam Üniversitesi Etik Kurulu'nun 27.03.2020 tarih ve E. 14223 sayılı toplantısında alınmıştır.

\section{Kaynakça}

Aitken, L., Currey, J., Marshall, A. ve Elliott, D. (2008). Discrimination of educational outcomes between differing levels of critical care programmes by selected stakeholders in Australia: A mixed-method approach. Intensive and Critical Care Nursing, 24(2), 68-77.

Anderson, D., Johnson, R. ve Milligan, B. (1998). Access to postgraduate courses: Opportunities and obstacles. Canberra: Higher Education Council, Commonwealth Department of Education. Training and Youth, Australia www.voced.edu.au/content/ngv\%3A41565 adresinden 22.03.2021 tarihinde indirilmiştir.

Austin, C. ve Vallely, P. (2014). Postgraduate research degrees, increasing awareness in schoolchildren. Widening Participation and Lifelong Learning, 16(3), 22-35.

Bandura, A. (1986). Social foundations of thought and action: A social cognitive theory. Englewood Cliffs, New Jersey: Prentice-Hall.

Barber, L., Pollard, E., Millmore, B. ve Gerova, V. (2004). Higher degrees of freedom: the value of postgraduate study. Report 410. South Coast: www.employment-studies.co.uk/system/files/resources/files/410.pdf adresinden 01.03.2021 tarihinde indirilmiştir. 
Betz, N. E. ve Hackett, G. (1986). Applications of self-efficacy theory to understanding career choice behavior. Journal of Social and Clinical Psychology, 4, 279-289.

Black, K. E. ve Bonner, A. (2011). Employer-based support for registered nurses undertaking postgraduate study via distance education. Nurse Education Today, 31(2), 163-167.

Bolat, N. ve Odac1, H. (2017). High school final year students' career decision-making self-efficacy, attachment styles and gender role orientations. Current Psychology, 36(2), 252-259.

Groube, J. K. (2017). Postgraduate Study: The Journey for registered nurses (Doctoral dissertation). University of Canterbury. New Zealand.

Hearn, J. C. (1987). Impacts of undergraduate experiences on aspirations and plans for graduate and professional education. Research in Higher Education, 27(2), 119-141.

Hu, L. T. ve Bentler, P. M. (1999). Cutoff criteria for fit indexes in covariance structure analysis: Conventional criteria versus new alternatives. Structural Equation Modeling: A Multidisciplinary Journal, 6(1), 1-55.

İlter, İ. (2020a). Öğretmenlerin lisansüstü eğitime katılımını teşvik eden etmenler ve bu eğitim sürecinde karşılaştıkları engeller. Kuram ve Uygulamada Ë̆itim Yönetimi Dergisi, 26(4), 905-944.

İlter, İ. (2020b). Akademik başarı, lisansüstü eğitim farkındalığ1 ve lisansüstü eğitim niyeti arasındaki ilişkiler. Ankara Üniversitesi Eğitim Bilimleri Fakültesi Dergisi, 53(1), 117-156.

Jepsen, D. ve Neumann, R. (2010). Undergraduate student intentions for postgraduate study. Journal of Higher Education Policy and Management 32(5), 455-466.

Jepsen, D. ve Varhegyi, M. M. (2011). Awareness, knowledge and intentions for postgraduate study. Journal of Higher Education Policy and Management, 33(6), 605-617.

Johnson, A. ve Copnell, B. (2002). Benefits and barriers for registered nurses undertaking post-graduate diplomas in paediatric nursing. Nurse Education Today, 22(2), 118-127.

Kline, R. B. (2015). Principles and practice of structural equation modeling. New York: Guilford Press.

Kulej, G. ve Wells, P. (2009). Higher education academy postgraduate research experience survey (PRES) 2009 results. The Higher Education Academy. www.heacademy.ac.uk/evidencenet adresinden 22.01.2020 tarihinde indirilmiştir.

Lee, S. J., Kim, S. ve Jung, J. (2020). The effects of a master's degree on wage and job satisfaction in massified higher education: The Case of South Korea. Higher Education Policy, 33(4), 637-665.

Lent, R. W., Brown, S. D. ve Hackett, G. (1994). Toward a unifying social cognitive theory of career and academic interest, choice, and performance. Journal of Vocational Behavior, 45(1), 79-122.

Lent, R. W., Brown, S. D. ve Hackett, G. (2000). Contextual supports and barriers to career choice: A social cognitive analysis. Journal of Counseling Psychology, 47(1), 36-49.

MacCallum, R. C., Browne, M. W. ve Sugawara, H. M. (1996). Power analysis and determination of sample size for covariance structure modeling. Psychological methods, 1(2), 130-149.

McCulloch, A. ve Thomas, L. (2013). Widening participation to doctoral education and research degrees: A research agenda for an emerging policy issue. Higher Education Research and Development, 32(2), 214-227,

McCulloch, A. ve Thomas, L. (2013). Widening participation to doctoral education and research degrees: A research agenda for an emerging policy issue. Higher Education Research and Development, 32(2), 214-227.

Neumann, R. (2003). The doctoral education experience: diversity and complexity. Evaluations and Investigations Programme, Research, Analysis and Evaluation Group (Canberra, Department of Education, Science and Training).

O'Grady, A. ve Cottle, V. (Eds.). (2015). Exploring education at postgraduate level: Policy, theory and practice. Routledge.

Ohnishi, S. ve Ford, J. H. (2015). Student seminar program for improving academic presentation skills for $\mathrm{PhD}$ students in science: The effect of language background on outcome. International Journal for Researcher Development, 6(1), 57-76.

Özyürek, R. (2013). Son zamanlarda geliştirilen kariyer gelişimi ile ilgili kuramları anlama ve uygulama. İçinde (Edit.) Spencer G. Niles - JoAnn Harris-Bowlsbey), 21. yü̈ynlda kariyer gelişimi müdabaleleri (Çeviri Editörü: Fidan Korkut Owen). Ankara: Nobel Akademik Yayınc1lik.

Park, C. ve Wells, P. (2010). The higher education academy postgraduate taught experience survey (PTES) 2010 report. www.improvingthestudentexperience.com/library/PG_documents/PTES_2010_final_report.pdf. adresinden 04.04.2021 tarihinde indirilmiştir.

Patton, W. ve Creed, P. A. (2001). Developmental issues in career maturity and career decision status. The Career Development Quarterly, 49(4), 336-351.

Pelletier, D., Donoghue, J., Duffield, C., Adams, A. ve Brown, D. (1998). Why undertake higher degrees in nursing? Journal of Nursing Education, 97(9), 422- 424.

Powell, D. F. ve Luzzo, D. A. (1998). Evaluating factors associated with the career maturity of high school students. The Career Development Quarterly, 47, 145-158.

Purcell, K., Elias, P., Atfield, G., Behle, H., Ellison, R., Luchinsaya, D., Snape, J., Conaghan, L. ve Tzanakou, C. (2012). Futuretrack Stage 4: Transitions into employment, further study and other outcomes. Manchester: Higher Education Careers Services Unit.

Richardson, A. ve Gage, J. (2010). What influences practice nurses to participate in post-registration education? Journal of Primary Health Care, 2(2), 142-149.

Savickas, M. L. (1984). Career maturity: The construct and its appraisal. Vocational Guidance Quarterly, 32, $222-231$. 


\section{İLTER}

Savickas, M. L. (1990). The use of career choice measures in counseling practice. In E. Watkins and V. Campbell (Eds.), Testing in counseling practice (pp. 373-417). Hillsdale, NJ: Erlbaum.

Schumacker, R. E. ve Lomax, R. G. (1996). A beginner's guide to structural equation modeling. Hillsdale, US: Lawrence.

Smith Report. (2010). One step beyond: Making the most of postgraduate education. www.bis.gov.uk/one-step-beyond adresinden 05.03.2021 tarihinde indirilmiştir.

Stuart, M., Lido, C., Morgan, M., Solomon, L. ve Akroyd, K. (2008). Widening participation to postgraduate study: Decisions, deterrents and creating success. York: Higher Education Academy.

Super, D. E. (1980). A life-span, life-space approach to career development. Journal of Vocational Behavior, 16, $282-298$.

Tabachnick, B.G. ve Fidell, S. (2013). Using multivariate statistics. New York: Pearson Press.

The British Academy. (2012). Postgraduate funding; the neglected dimension. London.

Ünsal, P. (2014). Donald Super'in mesleki yaşam dönemleri kuramı. (Edit. Pınar Ünsal), Kariyer gelişim kuramlar ve kariyer damısmanlĭğ. Ankara: Nobel Akademi Yay.

Wakeling, P. (2009). Social class and access to postgraduate education in the UK: A sociological analysis. (PhD thesis). University of Manchester.

Wang, R. (2018). Exploring education at postgraduate level: Policy, theory and practice. Innovations in Education and Teaching International, 55(2), 239-241.

Wisker, G. (2007). The postgraduate research handbook: Succeed with your MA, MPhil, EdD and PhD. Macmillan International Higher Education.

\section{EXTENDED ABSTRACT}

Postgraduate qualifications (both master's and doctoral levels) play an important role in raising the high-quality manpower required by societies. Postgraduate study is a high-level teaching activity that aims to raise qualified individuals who can guide individuals to graduate degrees, contribute to knowledge through scientific research processes and meet the needs of the developing industry and society. Postgraduate programs, which are an important part of higher education, have become a powerful way for graduates to define career paths in recent years. Postgraduate education is vital to the future health of universities and research and provides the advanced skills needed to grow the economy and support innovation and development. Postgraduate programs allow people to develop or change their field of study and career. Postgraduate teaching provides in-depth research into perspectives and key issues in education. The current study, which used a relational screening model, investigated the effect of the awareness towards postgraduate study (PG) on the PG study intentions among undergraduate students. It may be necessary to investigate potential factors that influence undergraduate students' intentions to pursue postgraduate studies in the future. This is because understanding these factors can help students have enough awareness of their competencies to make informed educational and professional decisions about their future. Exploring relationships in a study between the variables of postgraduate study awareness and postgraduate study intention can help university students better understand their postgraduate study goals and the process involved in shaping these goals. In this regard, it would be appropriate to conduct research aimed at identifying the possible variables that influence the decision to pursue postgraduate studies. The sample of the study consisted of 350 currently undergraduate students enrolled in the faculty of education in a university in Turkey. The postgraduate Study Awareness Scale and Postgraduate Study Intention Scale developed by the author were used to collect data for the study. Cronbach Alpha coefficients for the Postgraduate Study Awareness Scale and Postgraduate Study Intention Scale were calculated as .78 and 80, respectively. The data were analyzed by using Pearson product-moment correlation coefficient and structural equation modeling. The results of the correlation analysis revealed a moderately significant relationship between awareness of the postgraduate study and intention to pursue postgraduate study. Structural equation modeling results revealed that university students' awareness of postgraduate study positively predicted their intentions to pursue postgraduate study. The path from awareness to postgraduate study intention was found to be statistically significant. According to the findings of the study, students' awareness of postgraduate study positively influenced their intentions to continue pursuing postgraduate study. This finding indicates that, as expected, awareness of postgraduate study opportunities can have a significant impact on student's intention to undertake postgraduate study after completing their undergraduate degree. As a result, it can be stated that postgraduate study awareness has an intrinsic motivational effect on university students' thoughts about postgraduate study. The findings show that by examining students' levels of awareness about postgraduate study, postgraduate study intentions can be predicted. The use of awareness and information resources in the career development process, according to the researchers, would increase career maturity, which is defined as career decision-making competence (Patton, \& Creed, 2001; Powell, \& Luzzo, 1998, p. 145). In this sense, it can be said that awareness of postgraduate study is a critical factor that universities should 
consider when preparing students for academic life and employment (Jepsen, \& Varhegyi, 2011, p. 609). Raising students' awareness of postgraduate study can provide them with a variety of opportunities for future postgraduate study planning. This study yielded significant findings based on gaining insight into the level of awareness of students still enrolled in an undergraduate program about their thoughts on pursuing postgraduate study. Research in the literature has shown that the increased knowledge and awareness attributed to postgraduate study helps to increase career decision self-efficacy. Findings provide important clues for universities to give current undergraduate students a conscious awareness and understanding of postgraduate study opportunities in developing the idea of pursuing postgraduate study. Findings of this study indicate that if universities strive to increase participation, interest, and awareness for postgraduate study among current undergraduate students, this may have a positive impact on students' future postgraduate study decisions. Furthermore, it is believed that increasing students' awareness and knowledge of postgraduate opportunities will positively predict students' academic success. Students can then make decisions about whether to continue their studies or pursue postgraduate degrees. As a result, the idea of beginning postgraduate study should be implanted in the minds of students as early as possible to raise awareness. Thus, students starting undergraduate studies will understand this idea and have enough time to meet the academic achievement requirement and other requirements for postgraduate degrees. 